\title{
OS NOVOS PERFIS DA POLÍTICA: UM ESBOÇO ${ }^{1}$
}

NORBERT LECHNER

\section{Em memória de Pancho Aricó}

Quinze anos após a conferência regional da Clacso de 1978, na Costa Rica, que foi um marco ao estabelecer a democracia como o eixo do debate político-intelectual da América Latina, é oportuno lembrar que a democracia carece de um significado fixo e imutável, e, portanto, torna-se plausível reexaminar a ordem democrática atual. Nos anos 70, a questão da democracia emerge em oposição às ditaduras prevalecentes no Brasil e no Cone Sul. A antinomia democracia/ditadura imprime certo acento normativo à discussão, mas sem ingenuidade. Não nos enganamos quanto às dificuldades que as dramáticas desigualdades socioeconômicas e as divisões étnicas de nossos países impõem à coesão social e à integração política; as tradições populistas e clientelistas, às instituições representativas; a dinâmica da disputa intrapartidária, a um acordo sobre as regras do jogo; a persistência de uma "lógica de guerra", às relações cívico-militares; as reivindicações de justiça, a uma política de reconciliação. Inclusive houve, em famoso artigo de Germani, ${ }^{2}$ uma lúcida antecipação dos efeitos desestabilizadores que o avanço contínuo da secularização teria sobre a democracia. Mas, na época, não se visualizava o alcance da restruturação de nossas sociedades e seus efeitos sobre a política. Mesmo no Chile, onde se iniciou o projeto neoliberal e, portanto, onde se percebeu precocemente como

1 O presente texto foi apresentado na conferência sobre "A agenda aberta para a democracia na América Latina”, na Universidade Nacional de Córdoba (Argentina), realizada entre 8 e 10 de setembro de 1993. Uma versão anterior, "A democracia entre o realismo e a utopia", foi discutida no II Congresso de Filosofia e Política, organizado pela Uned, em Segóvia (Espanha), em abril de 1993. Publicado em Nueva Sociedad 130 (mar/abr 1994). Agradecemos ao editor da revista pela permissão para republicá-lo aqui

2 GERMANI, Gino. "Democracia e autoritarismo en la sociedad moderna" in VVAA: Los límites de la democracia, Clacso, Buenos Aires, 1985. 
ele alterava todas as relações sociais, destacou-se mais o efeito destrutivo sobre a política do que o novo significado. Talvez a reflexão tenha sempre um viés retrospectivo e nós não tenhamos conseguido nos adiantar ao tempo. O debate intelectual era sensível às transformações necessárias e havia preocupação com as novas formas de fazer política.

Durante toda a década de 1980, continua predominando uma visão defensiva (antiautoritária) da democracia. A motivação básica radica em fomentar os processos de democratização e apoiar a gestão governamental nas democracias emergentes. Paralelamente, tem-se mais consciência da grande transformação em curso. Não obstante, tende-se a focalizar separadamente os problemas da democracia e das mudanças socioeconômicas. Se todo esforço por um enfoque integrado se mostra precário, no caso latino-americano a cisão não surpreende devido à rapidez e à profundidade das alterações em curso. E mais: dado o caráter radical da mudança, que transforma simultaneamente a realidade social e as categorias interpretativas, nem chega a ser provável que possamos contar em breve com um enfoque adequado.

\section{A DEMOCRACIA POSSÍVEL}

Em um acelerado processo de vinte anos, o contexto da questão democrática na América Latina se alterou completamente. Hoje, a democracia realmente existente é determinada pelo fim de um ciclo histórico e pela reorganização integral das sociedades latino-americanas. ${ }^{3} \mathrm{O}$ discurso neoliberal é o que mais tem sabido sinalizar a reestruturação emergente: os ajustes estruturais alteram a matriz estadocêntrica das sociedades latinoamericanas, ${ }^{4}$ deslocando para o mercado a dinâmica do desenvolvimento social do Estado. Independentemente das especificidades do país, esse processo adquire uma força avassaladora devido ao seu caráter mundial. $\mathrm{O}$ colapso dos países socialistas consagra a globalização do regime capitalista

3 CALDERÓN, V. Fernando e SANTOS, Mario Dos : Hacia un nuevo orden estatal en América Latina. Veinte tesis sociopolíticas y un corolario de cierre, FCE, Santiago, 1991; PARAMIO, Ludolfo: Problemas de la consolidación democrática en América Latina en la década de los 90, Flacso, Série Contribuciones no 78, Santiago, 5/1992; WEFFORT, Francisco: Qual democracia?, Companhia das Letras, São Paulo, 1992.

4 CAVAROZZI, Marcelo. "Más allá de las transiciones a la democracia en América Latina" in Revista de Estudios Políticos n ${ }^{\circ}$ 74, México, 1991;Manuel GARRETÓN, Manuel y ESPINOSA, Malva: ¿Reformas del Estado o cambio en la matriz sociopolítica?, Flacso, Série Estudios Sociales n ${ }^{\circ}$ 30, Santiago, 8/1992. 
e, ao mesmo tempo, desnuda-lhe as contradições internas. Essa guinada drástica não se restringe ao "mapa-múndi" político-econômico; abrange também e acima de tudo os nossos mapas mentais. Presenciamos mudanças profundas nas tendências culturais, parcialmente manifestas no debate sobre a "pós-modernidade", que transformam nossa maneira de encarar o mundo e a vida. Em síntese, estamos em meio a uma grande transformação, semelhante aos processos de reorganização social dos anos 20 e 30, que nos obriga a repensar — e a refazer - as relações entre processos econômicos, formas políticas e pautas culturais.

A situação não pode ser mais dramática para a democracia na América Latina. A ordem democrática adquire um reconhecimento, que nunca foi tão extensivo na região, precisamente no momento em que uma mutação radical de contexto vem alterar o alcance e o sentido da democracia. Isso acrescenta uma complexidade adicional aos processos de transição e consolidação democráticas. A democracia deixa de ser um ponto de chegada determinado e conhecido e, por sua vez, encontra-se em transição. Anuncia-se a emergência de uma "nova democracia" diferente da ordem democrática existente. Tal mudança é ainda mais difícil de perceber e conceber à proporção que os atores e as instituições democráticas - aparentemente - não variam. No entanto, a continuidade formal oculta a emergência de novos significados. Com isso, a questão da democracia não pode deixar de ser uma indagação sobre a democracia possível. De que modo as transformações em curso afetam as condições de possibilidade da democracia na América Latina?

Em primeiro lugar, as possibilidades da democracia na América Latina estão condicionadas pelos processos de modernização. Democratização e modernização tendem a ser abordadas separadamente, privilegiando-se, em geral, o ajuste das estruturas produtivas e comerciais. Mas, a médio prazo, só parece viável uma estratégia de adaptação econômica que leve em conta, juntamente com as novas condições da economia mundial, os processos includentes da cidadania. As rebeliões populares, que eclodem de modo recorrente nas metrópoles da região, não respondem apenas a motivos econômicos, mas também a reivindicações de bom governo. Inversamente, o dinamismo da reestruturação econômica impõe a reorganização do funcionamento prático da democracia em nossos países, a adaptação dos mecanismos de condução política às condições de uma economia de mercado. "Imaginar que a cidadania possa ter plena vigência sem um esforço efetivo em matéria de competitividade revela-se, na década de 90, tão infundado quanto supor que a competitividade - ne- 
cessariamente de caráter sistêmico — se possa sustentar com atrasos importantes no âmbito da cidadania". 5 A compatibilidade postulada é razoável, mas, como sabemos, também problemática. ${ }^{6}$ Remete-nos não só aos problemas ancestrais de justiça social como também às representações simbólicas das novas tendências.

Um segundo referencial ineludível é aquele "ambiente" onipresente e inapreensível que denominamos cultura. Nossa delimitação do possível - e das possibilidades da democracia - depende, em última instância, dos mapas cognitivos com os quais interpretamos a realidade social. No caso latino-americano, isso implica assumir as formas híbridas com que uma sociedade mestiça concebe a modernização ${ }^{7}$ e a historicidade conflituosa em que sociedades tão divididas enfocam a cidadania. ${ }^{8}$ Mas, além disso, implica dar conta das atuais mudanças culturais. Presumindose que as nossas imagens da democracia possível e da ordem desejada dependem, afinal, dos mapas ideológicos e dos marcos conceptuais com que ordenamos o mundo, a crise das tais estruturas mentais afeta diretamente esses imaginários coletivos. No meu entender, um traço eminente da nossa época reside na erosão dos mapas cognitivos, desestruturando o campo do possível e turvando as utopias que cristalizam o sentido que atribuímos à democracia.

Por fim, torna-se indispensável contemplar as dinâmicas especificamente políticas. Uma vasta literatura sobre os processos de transição para a democracia tem sumariado os diversos fatores envolvidos, geralmente dando destaque à ação estratégica dos agentes e aos aspectos institucionais. De fato, as democracias latino-americanas costumam se caracterizar por uma frágil institucionalidade, incapaz de orientar o exercício conflituoso da cidadania. 9 Apesar da relevância da "engenharia institucional", os atuais processos de consolidação democrática estão condicionados por um elemento novo: a transformação da própria política. $\mathrm{O}$ novo contexto redefine o lugar e as funções da política e redimensiona o

5 Cepal: Educación y conocimiento - eje de la transformación productiva com equidad, Santiago, 1992, p. 18.

6 BRESSER, Luiz Carlos, MARAVALL, José M. y PRZEWORSKI, Adam . Economic Reforms in New Democracies. A Social-Democratic Approach, Cambridge University Perss, 1992

7 CALDERÓN, Fernando y HOPENHAYN, Martín . “Existe desarrollo sin identidad?”, Cepal, 1993, mimeo

8 ESCALANTE, Fernando: Ciudadanos imaginarios, El Colegio de México, 1992.

9 O'DONNELL, Guillermo "Democracia delegativa?" in Novos Estudos no 31, Cebrap, São Paulo, 1991. 
seu campo de competência. Altera não somente a política como também a cultura política. Tudo isso modifica os parâmetros habituais de concepção do político e, em suma, nos obriga a repensar o significado da democracia nas novas condições.

Prosseguindo, abordarei a atualidade da democracia de um ponto de vista específico: a dupla transformação da política (como prática institucionalizada) e do político (como o conjunto de formas em que imaginamos, vivemos e valorizamos a ordem ou, dito em termos democráticos, a comunidade de cidadãos). Interessa-me explorar, nas seções abaixo, algumas mudanças sofridas pela política da nossa época em virtude das transformações sócio-econômicas e culturais. Os cidadãos se ressentem de tais mudanças à luz de certa imagem familiar do que deve ser a política. Isto parece explicar o atual mal-estar com as formas de fazer política. Não obstante, esse cidadão imaginário, por sua vez, se acha em dissolução em consequiência da crise dos mapas ideológicos e dos códigos interpretativos em geral. Não se trata, porém, de uma despolitização, e sim de um processo de recomposição: estamos participando de uma redefinição dos sentidos da política e, portanto, da democracia possível. Uma advertência: tendo o Chile como referência, formularei minha interpretação em termos gerais, com o propósito exclusivo de descrever grosso modo as dinâmicas emergentes. Em defesa desta ambigüidade, espero que a perda em precisão seja compensada por uma perspectiva inovadora.

\section{A TRANSFORMAÇÃO DA POLÍTICA}

Múltiplos sinais indicam que estamos participando de uma profunda transformação da política institucionalizada. As mudanças englobam fenômenos muito diversos, de difícil classificação; afetam igualmente as democracias antigas e as novas, os governos de direita e os de esquerda, os regimes presidencialistas ou os parlamentaristas. Um primeiro passo consiste, pois, em descrever algumas das transformações em curso, a começar pela redefinição do próprio significado da política.

1. Que sentido(s) tem a política hoje em dia? Quando a sociedade moderna, secularizada, abandona todo princípio externo de legitimação e se vê obrigada a produzir — a partir de si mesma — suas normas de convivência, fica instaurado o primado da política como âmbito privilegiado de produção e reprodução da normatividade que rege a vida social. Assim, o significado da política moderna consiste, acima de tudo, 
na construção deliberada da ordem social. Essa concepção "construtivista" se opõe não só a princípios divinos e a tradições sacralizadas como também a visões "naturalistas" da ordem estabelecida, tal como as encontramos hoje em dia. O referencial histórico permite vislumbrar as transformações em curso. A política deixa de ser o lugar privilegiado da produção da sociedade por ela mesma à medida que as consequiências imprevistas e indesejáveis da ação política levam a duvidar de uma construção deliberada. A passagem de uma ordem recebida para uma ordem produzida, própria da modernidade, tende a ser reinterpretada mediante a idéia de uma ordem auto-regulada. Se concebermos o processo social em termos de uma auto-regulação, então, efetivamente, "é preciso renunciar à ilusão de que podemos criar deliberadamente o futuro da humanidade". ${ }^{10}$ Entretanto, a pretensão de eliminar a política não é menos ilusória. Assim sendo, qual é o lugar da política?

2. A interpretação da sociedade como um "sistema auto-regulado" questiona a centralidade da política. Em seu lugar, a ação política tende a operar mediante

"redes políticas". 11 Tais redes, formais ou informais, articulam um número variável de agentes (sociais, políticos, frações ou instâncias diferentes no interior do aparato estatal), interessados em negociar um acordo sobre determinada matéria. A decisão política já não representa um ato de autoridade que solicita obediência, e sim um acordo negociado, fundado em benefícios mútuos. Conquanto a diferença possa ser nula em casos concretos, trata-se de concepções distintas: atualmente, costuma-se conceber a política mais como um mecanismo de coordenação do que como instância de direção. Não obstante, as limitações de qualquer "auto-regulação social" exigem a intervenção política. Na medida em que a agenda política responde prioritariamente a questões conjunturais e imprevistas que exigem decisões imediatas, existe uma forte pressão em favor de um "decisionismo" à margem da coordenação e da cooperação com outros agentes.

3. Um aspecto decisivo da nova política advém da reestruturação do tempo. Sendo fundamentalmente voltada para o futuro, a sociedade moderna encontra no poder político um instrumento privilegiado para construir esse futuro; o amanhã deixa de ser um destino fatal e passa a ser abordado como um objetivo social. Por conseguinte, a ação

10 HAYEK, Friedrich. "El ideal democrático y la contención del poder" in Estudios Públicos No 1, Santiago, 1980, p.75.

${ }^{11}$ MARIN, Bernd e MAYNTZ, R. (eds.): Policy Netwoorks, Campus-Westview Press, 1991. 
política consiste primordialmente em decidir as metas e conduzir o processo social. Hoje em dia, dilui-se a fé no progresso que subjazia ao primado da política. O desvanecimento do futuro solapa a capacidade de condução política, que passa a ser mero manejo da contingência. A atual desestruturação do tempo e certa apologia de um "presente permanente" nos aproximam da experiência do mercado. Este se refere certamente a um horizonte de futuro, mas sob a forma de oportunidade e risco e inclusive de especulação; todavia, seu marco habitual é a conjuntura, ou seja, o afã de cada dia.

Em resumo, o mercado propõe desafios não objetivos. Conseqüentemente, uma conduta conforme com o mercado supõe um alto grau de flexibilidade, capaz de responder ágil e decididamente a tais desafios. Esta "lógica" econômica reorienta também a política; no lugar de uma ação estratégica adequada a objetivos, ela é concebida como uma gestão competitiva com relação aos desafios. De fato, hoje a ação política se confunde com a gestão pública.

4. Outro aspecto importante reside no deslocamento dos limites da política. Verifica-se uma reestruturação do campo político. Enquanto outrora o poder político se caracterizava precisamente por criar o seu próprio espaço - a nação —, o atual processo de globalização não só permeia como nunca permeou as fronteiras nacionais como também solapa a relativa congruência que existia entre os espaços políticos, econômicos e culturais. Por conseguinte, tanto a soberania nacional quanto a categoria de soberania popular, tão crucial para a idéia democrática, tornaram-se problemáticas. A antiga tensão entre democracia e capitalismo se expressa, atualmente, na distância entre a integração sistêmica da economia e da administração, que se produz em escala supranacional, e a integração política, que se realiza apenas no âmbito do Estado nacional. ${ }^{12}$ Se o déficit de legitimação democrática já suscita resistência na Comunidade Européia, muito mais temor produz na América Latina, onde é tradicionalmente débil a integração social por meio da cidadania. Aqui as dinâmicas externas sejam a dívida financeira, tarifas comerciais, circuitos audiovisuais, regulamentações ambientais, etc. — se impõem de modo direto e imediato, debilitando ainda mais os já precários "filtros" políticos.

A porosidade do território nacional assinala uma vasta reorganização do campo de competência da política. Observando os diagnósticos

12 HABERMAS, Jürgen . "Ciudadanía e identidade nacional. Consideraciones sobre el futuro europeo" in Debats No 39, Valência, 3/1992; HELD, David: "Democracy, the Nation-State and the Global System" in Economy and Society, XXV/2, 1991. 
sobre a ingovernabilidade de uma democracia sobrecarregada de demandas, a própria política tende a abdicar de suas responsabilidades em benefício de uma maior auto-regulação social. Contudo, no lugar de um fortalecimento da sociedade civil, nós vivemos o desdobramento da sociedade de mercado. De fato, a sociedade política se acha cada vez mais estritamente limitada pela sociedade econômica sob a forma de "imperativos técnicos". As decisões políticas são delimitadas pelos equilíbrios macroeconômicos que representam, mais do que um indicador, um verdadeiro princípio normativo a fixar limites rigorosos para a intervenção política. Sem dúvida, não deixa de ser saudável que a política não pretenda dirigir o processo econômico e, pelo contrário, respeite a lógica própria dos outros âmbitos; mas ela tende a discriminar responsabilidades, tanto que se faz necessário perguntar a que responde a política afinal.

5. As transformações apontadas, amplamente conhecidas, não dão conta da profundidade das mudanças. Um dos aspectos mais notórios da atualidade consiste na extensão do mercado a âmbitos não econômicos. Anteriormente, a referência à democracia como um mercado político, no qual as elites competem e no qual se intercambiam bens - p. ex., proteção e serviços em troca de lealdade e votos - , recorre a uma analogia. A analogia com o intercâmbio mercantil facilita a compreensão de certos processos políticos - p. ex., o clientelismo - , mas nem por isso anula a diferença entre economia e política. O limite se apaga quando o discurso da public choice pretende, explicitamente, estender a racionalidade do mercado ao campo político. O apelo a um "imperialismo econômico" tem sucesso, ainda que com resultados imprevisíveis. Em vez de uma maior liberdade de escolha do cidadão e de uma maior transparência das decisões políticas, a entronização da racionalidade econômica significa, primordialmente, a consagração de critérios mercantis na política: o dinheiro, a concorrência, o sucesso individual. À semelhança do frio mundo dos negócios, a política se tornou altamente competitiva e sumamente cara. Muda o estilo político, e o tradicional ethos da política como serviço público torna-se obsoleto. A corrupção mereceria uma análise mais profunda neste contexto. Tudo isso altera radicalmente os limites entre o público e o privado. Tradicionalmente, a democracia convocava indivíduos livres e iguais que, sem levar em conta seus atributos e interesses privados, decidiam sobre os assuntos da res pública. Ou seja, a democracia operava como a instância privilegiada de regulação e coordenação da vida social, paralela às funções coordenadoras que o mercado exerce para os indivíduos na qualidade de proprietários privados. $\mathrm{O}$ neoliberalismo, pelo contrário, pretende substi- 
tuir a política pelo mercado como instância máxima de regulação social. De fato, o atual avanço do mercado significa fortalecer o âmbito da coordenação entre privados, restringindo o espaço público. Assuntos outrora compartilhados por todos agora são privatizados, ou seja, subtraídos da esfera igualitária da cidadania. Neste sentido, as privatizações dos serviços públicos significam mais que medidas exclusivamente econômicas, avaliadas com critérios de eficiência e produtividade. No fundo, decide-se o que uma sociedade está disposta a compartilhar em termos de bens públicos. À medida que a noção de bem público se dilui, a referência à ordem coletiva torna-se vácua.

6. O avanço do mercado redefine o significado da política. Mas tal redefinição não depende só da dinâmica econômica. Uma das mudanças mais profundas da política provém das transformações culturais, especificamente o auge da cultura audiovisual. Vivemos numa cultura da imagem, na qual o espaço privilegiado é a televisão, com cujo acesso maciço a imagem substitui a palavra - e isso afeta a política, que tinha precisamente o discurso e a leitura como suportes tradicionais. Por esse motivo, é muito pertinente a pergunta de Oscar Landi: ${ }^{13}$ o que a televisão faz com a política? Por um lado, gera uma cisão entre a representação institucional e a representação simbólica da política. A televisão encena a política de acordo com as suas regras, modificando o caráter do espaço público. Por outro, promove um novo modo de ver a política. O processo comunicativo, no qual se fixa a agenda política, se constituem agentes, se geram expectativas e, principalmente, se erigem a legitimidade e a reputação públicas, apoia-se cada vez mais no impacto instantâneo de certas imagens. Usando uma linguagem audiovisual, o "look" do político pode gerar mais credibilidade do que um bom argumento. Mas a imagem é sempre ambígua, aberta a múltiplas leituras. A política levada à tela depende do contexto: o significado acaba se fragmentando e se recompondo tanto através da sequiência de imagens quanto do contexto cotidiano do espectador. As denúncias habituais de manipulação não dão conta do fenômeno. O meio televisivo está modificando tanto a atividade política quanto a percepção cidadã. A política se refrata em múltiplas vozes, e a partir de múltiplas imagens se constrói a opinião cidadã.

7. Menos visível do que o impacto audiovisual, conquanto mais relevantes, são os efeitos que a transformação da política pode ter sobre a "consciência coletiva" e, inversamente, os que as alterações de nossas estru- 
turas mentais podem ter sobre as instituições políticas. Não deixa de surpreender a desproporção entre a prioridade atribuída à política econômica e a ingenuidade com que abordamos a dimensão simbólica da política. Esquece-se que o desenvolvimento do Estado está estreitamente ligado à conformação da chamada "cultura nacional". Codificando a linguagem e o direito, homogeneizando os procedimentos burocráticos e a educação escolar, o Estado assegura formas comuns de percepção e raciocínio, marcos comuns de memória e perspectiva, ou seja, aquele "sentimento comum" no qual as pessoas se comunicam. Em face desse poder de totalização simbólica encarnado pelo Estado, ${ }^{14}$ acaso nós tomamos plena consciência do que a atual redefinição da política significa para a existência de um ponto de referência compartilhado por toda a sociedade? O viés antiestatista de nossas estratégias de modernização reduz a política a um mecanismo de regulação exclusivamente econômico, ignorando totalmente a criação política das estruturas comunicativas e das normas éticas nas quais se inserem os processos sociais. Em outras palavras: se toda economia de mercado pressupõe certo conformismo moral, hoje o drástico incremento dos riscos e das incertezas acentua a demanda de instâncias coletivas e de referências comuns e, portanto, exige mais produtividade da política. Por outro lado, presenciamos uma erosão de nossos mapas cognitivos.

\section{O MAL-ESTAR COM A POLÍTICA}

Habitualmente as análises da política não levam em conta $o$ político, sendo que essa experiência cotidiana das pessoas em relação com a ordem comum é a matéria-prima da qual se nutre a política institucionalizada. $O$ político escapa a qualquer definição substantiva e não se deixa fixar definitivamente; mas tampouco é um mero espaço virtual que se possa preencher com um conteúdo qualquer. ${ }^{15} \mathrm{O}$ político relaciona a vida social com a comunidade de cidadãos, circunscrevendo a constelação sempre variável dos múltiplos elementos que configuram a ordem. Refere-se a relações, mediações, proporções, por isso é tão difícil determiná-lo; mas ignorar "o político" significa amputar a política e reduzir o fenômeno político a suas formas visíveis. Quero dizer: limitando-nos à política institucionalizada, nós reforçamos exatamente esse caráter oculto da política

14 BORDIEU, Pierre. "Espreits d’Etat" in Actes de la Recherche Nos 96-97, Paris, 3/1993.

15 ARDITI, Benjamin. "Tracing the Political", 1993, mímeo 
que com tanta razão se denuncia. Por conseguinte, eu tentarei, a seguir, complementar a descrição das mudanças da política com uma exploração das transformações do político. Atualmente, uma abordagem fecunda do político consiste em refletir sobre o mal-estar com a política. No meu entender, existe hoje um amplo, mas silencioso, receio que não se deve confundir nem com rejeição da política nem com má vontade para com a democracia. Mencionando a dupla face desta, o protesto não se refere ao princípio de legitimidade, e sim à "democracia realmente existente". ${ }^{16}$ Creio que o mal-estar expressa uma reação contra as formas atuais de fazer política, acima descritas, à luz de uma imagem familiar do que é e do que deveria ser a política. Ao mesmo tempo, no entanto, essa idéia da política também parece estar mudando juntamente com as grandes transformações econômicas e culturais. Verifica-se uma redefinição do político ${ }^{17}$ sem que, por hora, se haja cristalizado uma nova visão. Em síntese, parece-me que o atual mal-estar com a política tem um duplo aspecto: assinala a continuidade de um imaginário coletivo e, ao mesmo tempo, expressa a busca de uma concepção nova.

Primeiramente, eu abordarei o mal-estar encarado como a dissonância entre a política, tal como a percebe a cidadania, e a imagem herdada da política. Podemos presumir que, entre as "evidências" básicas apenas explicitadas por serem óbvias - que configuram a(s) culturas(s) política(s) em nossos países, é provável que figure a imagem da política como a instância máxima de condução e proteção. Tal visão outorga ao poder político a sua aura. As pessoas esperam da política uma direção que decida sobre o possível, o provável e também sobre os objetivos desejáveis. Para o senso comum, a política deveria oferecer um projeto ou horizonte de futuro, com referência ao qual o presente se tornasse inteligível e previsível. Por outro lado, as pessoas esperam que a política as proteja contra os avatares do destino; que lhes garanta não só a integridade física e certa segurança econômica como também um referencial de certeza. Ante um presente aleatório e, em última instância, fútil, a política encarna uma promessa de continuidade e de duração.

À luz dessas premissas tácitas, a política institucionalizada causa mal-estar. Uma de suas manifestações consiste na falta de confiança nela e (quase certamente) nos políticos. A meu ver, essa desconfiança

16 MARAVALL, José Maria. “Las nuevas democracias, cultura política y legitimidad”, 1993, mímeo

17 MAIER, Charles (ed.): Changing Boundaries of the Political, Cambridge University Press, 1987 
traduz a impressão de que a política já não controla os processos sociais. A cidadania se vê acossada, de modo direto ou audiovisual, por um semnúmero de problemas - do desemprego à guerra, passando pela contaminação e a criminalidade - , cuja solução ela atribui à política ao mesmo tempo em que não lhe adjudica os benefícios que possa ter conseguido. A sensação de que "as coisas estão fora de controle" exprime um fracasso da política na medida em que, de fato, a ela se imputa um poder de controle sobre a realidade social.

Tal imputação não se justifica, tendo em vista o atual recuo da política e do Estado em favor da iniciativa privada e das forças do mercado. Não obstante, assinala a persistência de uma cultura política que continua acreditando no primado da política. Isso também se apresenta em outro aspecto.

Quando a condução política se restringe ao manejo da contingência, incapaz de balizar o futuro possível, o devir se torna imprevisível. À falta de previsão soma-se o desvanecimento de toda e qualquer noção de um amanhã melhor que dê sentido aos sacrifícios atuais. A política assim amesquinhada gera angústia, pois transfere toda a incerteza para o indivíduo. Sozinho, sem ponto de referência nem rede de segurança, ele há de tomar as decisões e assumir os riscos. Já não pode distinguir desejos e temores no tempo; a realidade se impõe, no seu imediatismo, qual um magma infinito. Oprimido, o cidadão acaba por abominar ou depreciar a política - suposta instância de proteção e condução - que o traiu.

A partir de sua experiência de isolamento e desamparo, o cidadão percebe a política como atividade auto-referente. Pode ser que ela leve em conta as suas demandas materiais, mas não há de cristalizar aquele "sentido de ordem" básico e comum que lhe serve de medida e referência. Por certo, há uma distância inevitável entre as inquietudes particulares e os assuntos públicos, entre governantes e governados, mas tal brecha se acentua quando já não se assume a política como o âmbito da representação geral da sociedade. Por parte do cidadão, debilitam-se os laços de pertinência à "comunidade de cidadãos" e, portanto, as questões políticas passam a lhe ser estranhas e indiferentes. Por parte das instituições, a responsabilidade política tende a se volatilizar. Se a democracia tem cada vez mais dificuldade de prestar contas à cidadania, isso se deve, em boa medida, ao fato de já não se saber ao certo do que a política é responsável. Os diversos sintomas de malestar - a falta de confiança, o sentimento de abandono e incerteza, a perda de identificação com os assuntos públicos, etc. - indicam ausências que, inversamente, configuram o imaginário coletivo sobre o que deve ser a 
política. Dela se espera condução, proteção, responsabilidade, códigos interpretativos. Estes elementos configuram as demandas de bom governo com as quais os cidadãos avaliam o fazer político.

\section{A TRANSFORMAÇÃO DO POLÍTICO}

Uma das características da nossa época consiste na rapidez com que as experiências do passado se tornam obsoletas e inúteis para fazer face aos desafios do presente. Esse desgaste também consome os imaginários coletivos e, concretamente, a imagem familiar da política. No novo contexto, é difícil reproduzir os símbolos e rituais, os afetos e valores que davam vida à democracia que conhecemos. Certa concepção do político está se esgotando. Na seção final, eu tentarei fazer um esboço dos fenômenos que anunciam uma redefinição.

1. Em primeiro lugar, chamo a atenção para a já mencionada crise dos mapas ideológicos. Na política - como nas cidades — nós precisamos nos orientar por mapas que delimitam o espaço, estabelecem hierarquias, prioridades e preferências, estruturam limites e clivagens sociais, assinalam metas e estratégias. As ideologias operam como esses mapas; ou seja, são mecanismos de redução de complexidade. Depois da polarização ideológica da década de 1960, temos aclamado o declínio das ideologias como um sinal de realismo. Em vez de reduzir a realidade a um esquema pré-fabricado, assume-se a complexidade social; porém mais informação não implica uma interpretação melhor. $\mathrm{O}$ desvanecimento dessas coordenadas amplia o espectro do possível, mas ao preço de debilitar o horizonte do desejável. Qual é a ordem desejada? Custa-nos designar os objetivos a que aspiramos e, portanto, a política parece ser uma justaposição de apostas arbitrárias. Em tal situação, geralmente se impõe o imediatismo raso dos interesses corporativos.

A ausência de objetivos sociais é acentuada pela dissolução dos eixos classificatórios habituais. A queda do muro de Berlim ilustra a derrocada de um esquema de amigo/inimigo que foi decisivo na estruturação do mapa político deste século. Menos visível é a desordem provocada pelo colapso dos topoi ou marcos ideológicos na vida cotidiana. Desfazem-se os limites entre nós e os outros e se perde o marco de referências e proporções que permite situar o lugar de cada um. Irrompe o elogio das diferenças, mas sem que se constitua uma "ordem de distinções". A invocação do pluralismo supõe uma articulação que ainda precisa ser reformulada. $\mathrm{Na}$ ausência de tal interação, a diversidade se manifesta como fragmentação. 
A crise dos mapas político-ideológicos aprofunda a falta de identificação cidadã com os partidos políticos. Em conseqüência de sua crescente burocratização e, sobretudo, das profundas transformações em escala mundial, ${ }^{18}$ os partidos políticos já não oferecem à cidadania pautas interpretativas que lhe permitam estruturar seus interesses e valores, suas preferências e medos, em identidades coletivas. Os partidos políticos ficam sem discurso; e os cidadãos, sem as coordenadas com as quais ordenavam os processos sociais e seu lugar neles. Trata-se de um processo cheio de vacilações. Por parte dos partidos políticos, mescla-se a defesa aguerrida de velhas senhas de identidade com a reformulação de objetivos e estratégias consonantes com a nova realidade. Crescem os partidos-ônibus (catch all parties) e emergem os "partidos transversais" (coalizão de frações), coisa que, por outro lado, debilita ainda mais o sistema partidário. Semelhante ambivalência caracteriza a experiência cidadã, na qual as imagens e identidades herdadas convivem com novas e difusas sensibilidades.

A erosão dos mapas ideológicos debilita as estruturas de comunicação e, portanto, as relações entre os cidadãos e a política. Os partidos políticos não conseguem aglutinar os múltiplos interesses segmentados e as sensibilidades tribais, substituindo opções programáticas por lideranças pessoais. Estas representam a única referência relativamente conhecida para a cidadania, dada a impossibilidade de antecipar a agenda efetiva das decisões políticas. À proporção que a política se identifica com uma gestão da conjuntura ou, diretamente, com uma gestão da crise, muda a participação política. Com exceção de algumas propostas gerais, baseadas nos programas eleitorais, a cidadania não consegue deliberar sobre a maior parte das opções. Conseqüentemente, a participação se desloca de uma deliberação prévia na tomada de decisões para uma avaliação ex post dos resultados. De fato, os direitos cidadãos começam a ser cada vez mais interpretados como direitos dos usuários de fiscalizar o realizado.

2. À mencionada crise dos mapas ideológicos parece subjazer uma "mutação" cultural muito mais profunda: uma verdadeira reestruturação dos mapas cognitivos. Eu me refiro às coordenadas mentais e aos códigos interpretativos mediante os quais tornamos inteligível a realidade social. O debate acerca da "pós-modernidade" tem revelado algumas dessas mudanças em curso que, a meu juízo, também anunciam uma transformação do político.

18 PARAMIO, Ludolfo. "Democracia, política, neoliberalismo" in Etcétera $\mathrm{N}^{\mathrm{o}}$ 1, México, 4/2/1993. 
A erosão de nossos mapas cognitivos se manifesta na desestruturação do tempo. Insisto num traço emblemático de tal fenômeno: o desvanecimento do futuro. Não só parecem ter se esgotado as energias utópicas, a nossa capacidade de imaginar outros mundos, a própria noção de futuro tende a se evaporar. A cultura do videoclip e do fast food estimula um consumo voraz e vertiginoso de modas, bens e valores. Nós devoramos o tempo em prazos cada vez mais breves, até ficarmos encerrados num presente permanente.

Semelhante ambiente cultural tensiona o político. Por um lado, como vimos, espera-se que a política institucionalizada compense esse imediatismo, oferecendo algo duradouro; por outro, contudo, o atual "curtoprazismo" na política não faz senão refletir esse clima cultural marcado pela consciência "fim de século" de uns e pelo fatalismo resignado de outros. Reina a ambivalência; a experiência cotidiana já não aposta nos grandes gestos e nas mudanças radicais, mas continua depositando na política a fé num amanhã melhor.

A falência dos mapas cognitivos também se expressa na reestruturação do espaço. Como conceber o ordenamento social se o nosso hábitat cultural está se dissolvendo em subculturas segmentadas? A sociedade contemporânea se caracteriza por um novo impulso de secularização que põe em dúvida a comunidade de crenças, normas e valores comuns que assegurava a coesão social. Emerge um novo individualismo que - mero voyeur da vida social - se retrai na intimidade do privado. No caso do Chile é notório como a privatização econômica vem se desdobrando numa verdadeira privatização dos indivíduos, que abrem mão dos assuntos públicos em benefício de uma acomodação pessoal às oportunidades e desafios. Tal privatização fomenta atitudes racionais e criativas no âmbito individual, mas irresponsáveis no referente aos bens públicos. Desenvolve-se um cálculo custo-benefício utilitarista que desconfia de todo compromisso coletivo. A própria ética deixa de ser uma normatividade para se restringir à esfera da consciência individual. Pois bem, ao constatar o declínio do homem público, ${ }^{19}$ não se pode esquecer que os indivíduos tendem a enfatizar seus interesses públicos ou suas preferências privadas de acordo com certos ciclos históricos. ${ }^{20}$ Ademais, parece razoável que os indivíduos privilegiem a própria particularidade, dados a generalidade abstrata do Estado

19 SENNETT, Richard. El declive del hombre público, Península, Barcelona, 1978

20 HIRSCHMAN, Albert. Shifting Envolvement: Private Interest and Public Actors, Princeton University Press, 1982. 
e o anonimato uniforme do mercado. Mas isso não faz senão ressaltar o desafio iminente: reconstruir — em novas condições - a integração das vidas individuais a uma ordem coletiva. No fundo, a própria categoria sociedade precisa ser repensada.

O enfraquecimento das estruturas comunicativas dilui o "cimento" normativo e efetivo da democracia e nos obriga a repensar o que hoje significa a comunidade de cidadãos. ${ }^{21}$ Cabe indagar, por exemplo, o que é pertencer a uma comunidade política quando os cidadãos estão dispersos em pequenos circuitos ou tribos locais, formando arquipélagos com escassa comunicação entre si. Mas, além das identidades coletivas, a identidade individual também é posta em dúvida. O próprio indivíduo, longe de construir aquela "unidade de medida" básica, se descobre um ser contraditório, cujos valores e crenças, atribuições herdadas e aflições adquiridas se sobrepõem e se entremesclam como estratos de nuvens em movimento contínuo.

Outra indagação aponta para a identificação com a democracia quando se diluem as representações coletivas. Por meio de que mitos, símbolos e rituais o cidadão pode se identificar com a ordem democrática? $\mathrm{O}$ avanço da secularização privou a cidadania, inclusive o ato eleitoral, de sua aura. Desagrega-se a ordem simbólica que configura o "espírito" das leis e instituições. No entanto, a adesão à institucionalidade democrática e às normas constitucionais, mesmo sendo apenas uma lealdade passiva, não pode prescindir desses mecanismos de identificação. De fato, as recentes mobilizações cidadãs contra tentativas golpistas e escândalos de corrupção exteriorizam um compromisso com a democracia. Mas, por ora, trata-se de uma reação defensiva destinada a marcar os limites — o ponto de não retorno - , mas sem determinar as novas fronteiras. Falta avançar além dos esforços para definir o que é e o que não é democracia ${ }^{22}$ e dar conta das dinâmicas, leves e pesadas, que configuram as tendências emergentes.

NORBERT LECHNER, cientista social chileno, foi pesquisador da FLACSO (Chile e México).

${ }^{21}$ LECHNER, Norbert. "The Search for Lost Community. Challenges to Democracy in Latin America" in International Social Science Journal $\mathrm{N}^{\mathrm{o}}$ 129, Unesco, 1991; LECA, Jean: "Questions on Citizenship" in MOUFFE, Chantal (ed.): Dimensions of Radical Democracy, Verso, Londres, 1992.

22 SCHMITTER, Philippe e KARL, Terry L. "What Democracy is and is not?" in Journal of Democracy $\mathrm{N}^{\circ}$ 3, 1991. 